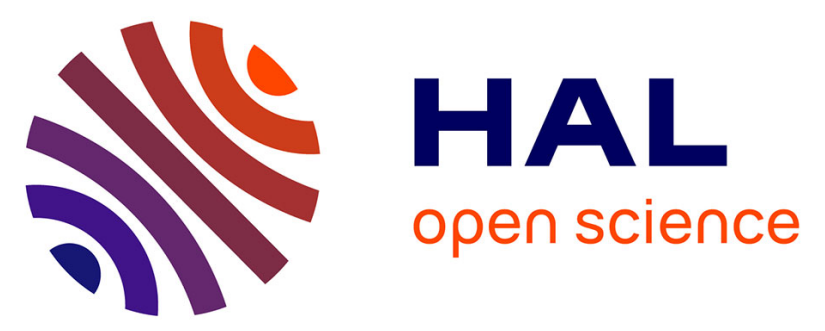

\title{
Characterization and genetic mapping of a new blood-flesh trait controlled by the single dominant locus DBF in peach
}

Zhijun Shen, Carole C. Confolent, Patrick Lambert, Jean-Luc Poessel, Bénédicte Quilot-Turion, Mingliang Yu, Ruijan Ma, Thierry Pascal

\section{To cite this version:}

Zhijun Shen, Carole C. Confolent, Patrick Lambert, Jean-Luc Poessel, Bénédicte Quilot-Turion, et al.. Characterization and genetic mapping of a new blood-flesh trait controlled by the single dominant locus DBF in peach. Tree Genetics and Genomes, 2013, 9 (6), pp.1435-1446. 10.1007/s11295-0130649-1 . hal-02648172

\section{HAL Id: hal-02648172 \\ https://hal.inrae.fr/hal-02648172}

Submitted on 29 May 2020

HAL is a multi-disciplinary open access archive for the deposit and dissemination of scientific research documents, whether they are published or not. The documents may come from teaching and research institutions in France or abroad, or from public or private research centers.
L'archive ouverte pluridisciplinaire HAL, est destinée au dépôt et à la diffusion de documents scientifiques de niveau recherche, publiés ou non, émanant des établissements d'enseignement et de recherche français ou étrangers, des laboratoires publics ou privés. 
Version préliminaire du manuscrit publié dans / Preliminary version of the manuscript published in :

Tree Genetics and Genomes (2013), 19 p., DOI: no data

Journal homepage: http://link.springer.com/journal/11295

Manuscript for Review

\section{Characterization and genetic mapping of a new blood-flesh trait controlled by the single dominant locus DBF in peach}

\begin{tabular}{|r|l|}
\hline Journal: & Tree Genetics and Genomes \\
\hline Manuscript ID: & TGG-2013-0042.R1 \\
\hline Manuscript Type: & Original Paper \\
\hline Date Submitted by the Author: & n/a \\
\hline Complete List of Authors: & $\begin{array}{l}\text { Shen, Zhijun; JAAS, } \\
\text { Confolent, Carole; INRA, } \\
\text { Lambert, Patrick; INRA, } \\
\text { Poessel, Jean-Luc; INRA, } \\
\text { Quilot, Benedicte; INRA, } \\
\text { Yu, Mingliang; JAAS, } \\
\text { Ma, Ruijan; JAAS, } \\
\text { Pascal, Thierry; INRA, }\end{array}$ \\
\hline Keywords: & $\begin{array}{l}\text { Prunus persica, anthocyanin, mesocarp, SSR, genetic map, candidate } \\
\text { genes, PprMYB10 }\end{array}$ \\
\hline
\end{tabular}


Version préliminaire du manuscrit publié dans / Preliminary version of the manuscript published in :

Tree Genetics and Genomes (2013), 19 p., DOI: no data

1 Journal homepage: http://link.springer.com/journal/11295

Characterization and genetic mapping of a new blood-flesh trait controlled by the single dominant locus $D B F$ in peach

\title{
Zhijun Shen - Carole Confolent - Patrick Lambert - Jean-Luc Poëssel · Bénédicte Quilot-Turion • Mingliang Yu $\cdot$ Ruijan Ma $\cdot$ Thierry Pascal
}

Zhijun Shen $\cdot$ Mingliang Yu $(\bowtie) \cdot$ Ruijan Ma

Institute of Horticulture, Jiangsu Academy of Agricultural Sciences, Nanjing 210014, People's Republic of China

email:mly1008@yahoo.com.cn

Carole Confolent · Patrick Lambert · Jean-Luc Poëssel · Bénédicte Quilot-Turion · Thierry Pascal ( $ه)$

INRA, UR1052, Genetics and Breeding of Fruit and Vegetables, Domaine St Maurice - Allée des Chênes CS 60094 F-84143 MONTFAVET Cedex, France

email: tpascal@avignon.inra.fr

\begin{abstract}
Anthocyanin-rich peaches, because of their antioxydant properties and their strong attractiveness to consumers, are increasingly considered in French peach varietal innovation programs that integrate plant genomics and classical breeding. In this study, we describe a new blood-flesh trait identified in the 'Wu Yue Xian' peach accession from China. 'Wu Yue Xian' exhibits a fully red mesocarp during the later stages of fruit development, both with green midrib leaf and normal growth of the tree. This blood-flesh phenotype clearly differs from that determined by a single recessive locus $(b f)$ in 'Harrow Blood', a clone showing blood-flesh in both immature and mature fruit associated with red midrib leaf and reduced tree height. We have then provided genetic evidence that blood-flesh phenotype of 'Wu Yue Xian' was controlled by a single dominant locus, designated $D B F$, in four successive families derived from this accession. A genetic linkage map of the bloodflesh parent ('D6090') of the fourth population was constructed, including 102 SSRs spanning a total distance of $562.3 \mathrm{cM}$ in 8 linkage groups. Whereas the $b f$ locus is located to linkage group 4 , we mapped $D B F$ to the top of linkage group 5, thus proving that $D B F$ and $b f$ loci are not alleles. Among 64 predicted genes in the $D B F$ region $(505 \mathrm{kbp})$, three genes of the dihydroflavonol-4-reductase family were identified as good candidates for the control of the $D B F$ trait. Furthermore, SSR markers flanking $D B F$, such as AMPP157 and AMPPG178, supply a good basis to implement marker-assisted selection for this trait.
\end{abstract}

Keywords: Prunus persica, anthocyanins, mesocarp, SSR markers, genetic map, candidate gene, PprMYB10

\section{INTRODUCTION}

Anthocyanins are flavonoid pigments that are responsible for the red, blue and purple pigmentation of fruits, flowers, foliage, seeds and roots (Tanaka et al. 2008). They play important ecophysiological roles in both abiotic and biotic stress resistance in plants, as pollination attractants in flowers and in seed dispersal and protection against UV light damage (Feild et al. 2001; Regan et al. 2001; Winkel-Shirley 2001). The accumulation of 
Version préliminaire du manuscrit publié dans / Preliminary version of the manuscript published in :

Tree Genetics and Genomes (2013), 19 p., DOI: no data

1 Journal homepage: http://link.springer.com/journal/11295

anthocyanin pigments in fruit and vegetables is also an important determinant of ripeness and quality. Anthocyanin-rich fruits and vegetables are brighter and more attractive to consumers, making them more marketable. Recently, anthocyanins have attracted even more interest from the public and the research community due to their potential to positively impact human health based on their antioxidant properties. It has also been suggested that anthocyanins can reduce the incidence of certain cancers, coronary heart diseases, oxidative stress and other age-related diseases (Butelli et al. 2008; Williams et al. 2008; Dragsted et al. 2006; Shin et al. 2006; Vinson et al. 2005; Ross and Kasum 2002). Their association with human health, particularly their capacity for pigmentation, has led to an increased demand among consumers for anthocyanin-containing products and to plant breeders doubling their efforts to identify natural foods, especially fruits, that are rich in anthocyanins. For these reasons, the investigation of anthocyanin biosynthesis in fruit has become a popular area of research, with the aim of more efficiently developing novel fruit cultivars with a higher anthocyanin content (Xie et al. 2011). In addition to well-known anthocyanin-rich fruits such as blueberries or cranberries, other fruits with red flesh, such as kiwis (Jaeger and Harker 2005), oranges (Xu et al. 2009), apples (Sekido et al. 2010; Volz et al. 2009), plums (Cevallos-Casals et al. 2006) and cherries (Sooriyapathirana et al. 2010), are considered in varietal innovation programs, which generally integrate plant genomics and classical breeding methods.

In the peach, Prunus persica (L.) Batsch, red color is a key fruit trait, which contributes to the attractiveness of both peaches and nectarines (Scorza and Sherman 1996). Most of peach cultivars exhibit fruits with fully red skin, which is commonly associated, for a number of them, with red pigmentation of the mesocarp around the stone appearing generally with the later stages of fruit ripening (Hsia et al. 1965; van Blaricom and Senn, 1967). The presence of red color around the stone, due to anthocyanins, is determined by the single dominant Cs locus and was mapped to LG3 from the Japan peach cultivar 'Juseito' (Yamamoto et al. 2005; 2001). However, as in many other rosaceous fruit species (Cevallos-Casals et al. 2006), some variants of these cultivars exhibit an intensely pigmented fruit mesocarp with a red-violet color, referred to here as blood-flesh peach, that represent an attractive starting point for the development of novel fruit varieties with a high anthocyanin content. Chaparro et al. (1995) were the first to thoroughly describe a blood-flesh phenotype from 'Harrow Blood', a Canadian peach cultivar characterized by the presence of high levels of anthocyanins in the mesocarp of unripe and ripe fruit, associated with a red midrib color on the abaxial side of the leaf. Anthocyanin accumulation in the fruit mesocarp of 'Harrow Blood' was initiated at about the onset of pit hardening, approximately 45-50 days after anthesis, exhibiting a red pigmentation gradient from the epidermis to stone. This early expression differed from that generally associated with the later stages of ripening in standard cultivars, as described above, providing a criterion for distinguishing blood-type from non-blood-type traits. Werner et al (1998) have then demonstrated that the blood-flesh phenotype of 'Harrow Blood' was controlled by a single recessive locus, designated $b f$ (blood-flesh). This blood-flesh phenotype was associated with reduced tree height in progeny derived from this cultivar. Gillen and Bliss (2005) mapped the $b f$ locus to the top of linkage group (LG) 4.

Genotypes carrying the $b f$ gene have long been employed in peach breeding programs, especially in France (Pascal and Monteux-Caillet 1998), as demonstrated by the varietal range of 'Nectavigne ${ }^{\circledR}$, (www.nectavigne.fr/). However, the development of such cultivars is limited by the two generations required to introgress the recessive blood-flesh trait into non blood-flesh commercial cultivars. Furthermore, although blood-flesh progeny generally produce fruit with anthocyanin that is distributed throughout the mesocarp, some 
Version préliminaire du manuscrit publié dans / Preliminary version of the manuscript published in :

Tree Genetics and Genomes (2013), 19 p., DOI: no data
2 Journal homepage: http://link.springer.com/journal/11295

3

4

5

6

progeny bear fruit in which anthocyanin is only localized in the outer mesocarp (Werner et al. 1998). We have thus developed a complementary breeding program based on the use of another blood-flesh type observed in the 'Wu Yue Xian' cultivar (clone S 4566), which is similar to the one described by Werner et al. (1998) in 'Indian Cling'. 'Wu Yue Xian' is a Chinese peach cultivar that was initially introduced in France in the early 1980s. Other similar blood-flesh peach cultivars have been grown in China for hundreds of years, with some being traced back as far as the Tang Dynasty, 800 years ago (Wang and Zhuang 2002). According to the traditional Chinese classification of peach cultivars, blood-flesh peaches belong to the crisp peach group because of their crisp texture just before maturity and their mealiness, in most cases, when fully matured ( $\mathrm{Lu}$ et al. 2010). Currently, blood-flesh peaches are mainly cultivated along the middle reaches of the Yangtze River in central China, where consumers traditionally prefer this type of landrace. The blood-flesh inheritance of these peach landraces has not been described previously, but their phenotype is morphologically similar to that exhibited by 'Wu Yue Xian'. Because the genetic determinism of the latter cultivar was still unknown, the objectives of this work were (1) to characterize the phenotype of the new blood-flesh trait of 'Wu Yue Xian' compared to that determined by the $b f$ locus, (2) to study its mode of inheritance and (3) to map it to the peach genome to implement marker-assisted selection (MAS) and to initiate a candidate gene approach for this trait.

\section{Material and methods}

Plant material

Two groups of blood-flesh accessions were examined to identify dissimilar features between the 'Wu Yue Xian' and $b f$-type phenotypes. The first group, in addition to 'Wu Yue Xian', included one peach, 'I138', and two nectarines, 'D6090' and 'D7070', derived from 'Wu Yue Xian'. The second group was composed of three old French blood-flesh peach cultivars, 'Sanguine Pilat', 'Sanguine Vineuse' and 'Sanguine Super Tardive', and three blood-flesh nectarines, 'R6041', 'R6044' and 'R6057', derived from the former three cultivars. All of the advanced selections used in this trial ('I138', 'D6090', 'D7070', 'R6041', 'R6044', 'R6057') were developed at the INRA Genetics and Breeding of Fruit and Vegetables Unit in Avignon (France).

Four populations were used to study and map the blood-flesh trait found in 'Wu Yue Xian' (Fig. 1). These four successive crosses were performed between 1983 and 2006, involving hybridizations between commercial cultivars (as mother trees) and blood-flesh pollinators derived from 'Wu Yue Xian'. The fourth population, 'Honey Blaze ${ }^{\circledR}$, $\times$ 'D6090' (HD) was finally chosen as the genetic mapping population. This population consisted of 80 individuals segregating for the blood-flesh trait. All of the populations and the parents were grown at the INRA "Domaine des Pins de L'Amarine” Experimental Farm (France). Trees were planted on their own roots in orchards, spaced 1 meter apart within a row, with 4 meters between rows, and grown under optimal conditions of irrigation, fertilization, pruning and pest control.

Plant phenotyping

To compare the two blood-flesh phenotypes, we examined the petioles, stems, leaves and fruits of each progeny belonging to both groups listed above according to the rating system defined by Chaparro et al. (1995). Six 
Version préliminaire du manuscrit publié dans / Preliminary version of the manuscript published in :

1 Tree Genetics and Genomes (2013), 19 p., DOI: no data

1 Journal homepage: http://link.springer.com/journal/11295

selections, 'D6090', 'D7070', 'I138', 'R6041', 'R6044' and 'R6057', were the most thoroughly studied. To record the appearance and measure the temporal progression of red pigmentation in the mesocarp during fruit development, 10 fruits from each selected genotype were collected in the orchard in several steps from fruitlet thinning to maturity. Fruit samples were brought back to the laboratory and cut into two parts following the suture. The stone was either cut into two parts or removed. The two flesh sections were scanned for further analysis using ImageJ software (available at http://rsb.info.nih.gov/ij/; developed by Wayne Rasband, National Institutes of Health, Bethesda, MD). Along the radius of the fruit, the lengths of the whole flesh and blood-flesh were measured to estimate the proportion of blood-flesh. The average blood-flesh proportion in a given fruit was calculated from four measurements (two in each fruit section).

For the four populations derived from 'Wu Yue Xian', the blood-flesh trait was stable across the years (e.g., 1985-2005) and could be reliably and simply characterized in ripe fruits in the orchard based on the presence or absence of a fully red mesocarp. Therefore, in this work, blood-flesh was scored as a qualitative trait (blood / nonblood) in the four populations, including the HD mapping population. All phenotypic evaluations carried out in the orchard were performed systematically over two successive years for each population in adult trees that were at least three years old.

DNA isolation

Samples of young leaves from the HD mapping population and the two parents were collected in June 2012. Isolation of genomic DNA from the parents was performed as previously described (Bernatzky and Tanksley, 1986) to obtain a sufficient amount of DNA. DNA from the progeny was isolated using the DNeasy ${ }^{\circledR}$ Plant Mini kit (Qiagen, MD USA) following manufacturer's instructions. The obtained DNA concentrations were measured using a Thermo Scientific NanoDrop ${ }^{\mathrm{TM}}$ spectrophotometer, and DNA quality and yield were assessed via electrophoresis in $1.0 \%$ agarose gels.

SSR marker analysis

SSR primer pairs used in this study were the same as those used by Lambert and Pascal (2011), except for the new SSR developed from the Prunus persica v1.0 genome sequence (http://www.rosaceae.org/species/prunus_persica/genome_v1.0). A total of 508 SSRs from different Prunus species were screened between the two parents using two different methods. Those for which dye-labeled primers were available were amplified with FAM, HEX or NED dye-labeled forward primers and the standard reverse primer. PCR products were mixed and diluted 80 times, then loaded into an ABI 3730xl DNA Analyzer (Applied Biosystems, Foster City, CA, USA), using Genescan 500 LIZ (Life Technologies SAS) as size standard. The others were amplified with standard primer pairs. PCR products were then separated by electrophoresis on $3.0 \%$ agarose gels and stained by EB (Ethidium bromide). For both methods, PCR reactions were performed in a total volume of $15 \mu \mathrm{l}$, containing $15 \mathrm{ng}$ of template DNA, $1 \mathrm{X}$ of buffer, $1.5 \mathrm{mM}$ of $\mathrm{MgCl}_{2}$, $0.2 \mathrm{mM}$ of dNTPs, $0.25 \mathrm{U}$ of GoTaq polymerase (Promega), and $0.2 \mu \mathrm{M}$ of each primers. They were carried out in a Mastercycler ${ }^{\circledR}$ ep gradient thermal cycler (Eppendorf GmbH, Germany) using a program of 3 min at $94{ }^{\circ} \mathrm{C}$, followed by 35 cycles consisting of $94^{\circ} \mathrm{C}$ for $45 \mathrm{~s}, 52-57^{\circ} \mathrm{C}$ (according to the $\mathrm{Tm}$ of each primer) for $45 \mathrm{~s}$, and 
Version préliminaire du manuscrit publié dans / Preliminary version of the manuscript published in :

1 Tree Genetics and Genomes (2013), 19 p., DOI: no data

1 Journal homepage: http://link.springer.com/journal/11295

$72^{\circ} \mathrm{C}$ for $60 \mathrm{~s}$, with a final extension of $10 \mathrm{~min}$ at $72^{\circ} \mathrm{C}$. Polymorphic SSRs at least heterozygous for one parent were then used for mapping the whole population. SSRs showing alleles with sufficiently different sizes between parents were run on agarose gels and the others using the ABI 3730xl.

SSR marker development

New SSRs (Table 4) were previously developed from the Prunus persica v1.0 genome sequence using Sputnik software (Abajian 1994) under the framework of other studies (not published). Once the blood-flesh trait was mapped, additional SSR loci were developed in the region surrounding the blood-flesh locus from 'Wu Yue Xian'. This region was identified in LG5 by comparing the primer sequences used for the already-mapped adjacent SSRs with the peach genome sequence. SSRs were then selected with Sputnik software, and primer pairs were designed with Primer3 software (http://primer3.wi.mit.edu/).

Linkage map construction

Due to the low level of heterozygosity observed in 'Honey Blaze ${ }^{\mathbb{B}}$, a genetic map was only constructed for 'D6090', the donor of the blood-flesh trait, following the "double pseudo-testcross" model of analysis previously described by Lambert and Pascal (2011). Markers that were heterozygous in 'D6090' and homozygous in 'Honey Blaze ${ }^{\circledR}$, or heterozygous in both parents, but with at least one different allele, were scored for the presence/absence of the allele considered. Departure from the 1:1 ratio expected for a backcross population was tested using the chi-square goodness-of-fit test $(\mathrm{P}<0.05)$. Linkage analysis was performed with MAPMAKER/EXP V3.0 software (Lincoln et al. 1992). Linkage groups were initially established using a logarithm of the odds (LOD) threshold of 3.0 and a recombination fraction of 0.30 . Marker distances were calculated using the Kosambi mapping function (Kosambi 1944), and map figures were obtained using MapChart software (Voorrips 2002). Marker positions and order were compared to those in the 'Texas' $\times$ 'Earlygold' $(\mathrm{T} \times \mathrm{E})$ genetic map which is considered the reference map for Prunus (http://www.rosaceae.org/maps).

In silico candidate gene research

We first investigated the location of PprMYB10, peach homolog of MdMYB10, a MYB transcription factor gene responsible for both red foliage and red-fleshed fruit in apple (Espley et al. 2009). PprMYB10 homolog has been identified by Lin-Wang et al. (2010) together with MYB10 from other Rosaceae species through homology cloning based on the MdMYB10 sequence. We identified the location of PprMYB10 through alignment of the coding sequence of the gene (GenBank accession EU155160) with the peach genome v1.0 using BLASTN analysis (BLASTN 2.2.18) on the Genome Database for Rosaceae server (http://www.rosaceae.org) to test for a possible co-location of PprMYB10 with the mapped red-flesh trait found in 'Wu Yue Xian'.

To perform a preliminary search for other candidate genes (CGs), we downloaded from the Genome Database for Rosaceae (http://www.rosaceae.org/species/prunus_persica/genome_v1.0) the Prunus persica v1.0 genome homology files including predicted genes and annotation data. Functional annotations of predicted genes 
Version préliminaire du manuscrit publié dans / Preliminary version of the manuscript published in :

Tree Genetics and Genomes (2013), 19 p., DOI: no data

1 Tree Genetics and Genomes (2013), 19 p., DOI: no data

located in the region containing the red-flesh locus were screened and structural and regulatory genes possibly involved in the anthocyanin pathway were selected.

Statistical analysis

The segregation ratios recorded in the blood-flesh trait inheritance analysis were further tested using the chisquare goodness-of-fit test $(\mathrm{P}<0.05)$.

\section{Results \\ Comparison of the two blood-flesh phenotypes}

To determine whether the blood-flesh phenotype of 'Wu Yue Xian' was different from that reported in 'Harrow Blood', we compared red color expression in different organs in the two groups of blood-flesh genotypes. The results summarized in Table 1 showed that all of the genotypes in the first group exhibited the same blood-flesh phenotype. Neither early expression of red pigmentation in the mesocarp of the unripe fruits, nor red midrib leaf (Fig. 2) were observed on these plants. Their blood-flesh phenotype was mainly characterized by the presence of intense red color in the mesocarp of ripe fruits, which was the only feature common to both groups. The bloodflesh phenotype of the accessions in the second group, which included 'Sanguine Pilat', 'Sanguine Vineuse', 'Sanguine Super Tardive', 'R6041', 'R6044' and 'R6057', was similar to that described in 'Harrow Blood'. Their blood-flesh phenotype was mainly characterized by high levels of anthocyanin pigmentation in the mesocarp of unripe and ripe fruits, associated with the presence of red leaf midrib, as previously described in 'Harrow Blood' (Chaparro et al., 1995). The stems (Table 1, Fig. 2) and petioles of the genotypes in the second group were more intensively pigmented than those of the first group.

With respect to the occurrence and progression of anthocyanin accumulation in the mesocarp during fruit development (Fig. 5), red pigmentation was largely not observed during fruit development in 'D6090', 'D7070' and 'I138'. Red pigmentation began to be detected in the mesocarp close to fruit maturity, with rapid progression of the red pigmentation occurring thereafter, increasing from zero to $100 \%$ over 10 days. In contrast, an early occurrence of the red pigmentation in the mesocarp was observed for 'R6041', 'R6044' and 'R6057' (Fig. 5). This pigmentation began approximately 40-50 days after blooming and showed regular progression until fruit maturity.

In addition, the red pigmentation of the fruit mesocarp was more intense in 'Wu Yue Xian' and completely masked the white or yellow base color of the flesh (Fig. 3), which was rarely observed in the other blood-flesh phenotype (Fig. 4). The color of the red pigmentation in the mesocarp of group 1 was brighter and less red-violet than that observed in fruits from the other blood-flesh-type peach (Fig. 4). No differences in vigor were observed in the orchard based on visual inspection of the populations derived from 'Wu Yue Xian' segregating for the blood-flesh trait in contrast with progenies derived from French old blood-flesh cultivars.

Inheritance of the new blood-flesh trait borne by 'Wu Yue Xian' 
Version préliminaire du manuscrit publié dans / Preliminary version of the manuscript published in :

1 Tree Genetics and Genomes (2013), 19 p., DOI: no data

1 Journal homepage: http://link.springer.com/journal/11295

No difficulty was encountered in discriminating between blood-flesh and non blood-flesh fruits in the four populations derived from 'Wu Yue Xian' (Fig. 3). The results presented in Table 2 show that all 159 individuals derived from the first controlled cross between 'Wu Yue Xian' and 'Redtop' displayed blood-flesh. The other three populations exhibited segregation ratios close to $1: 1$ for blood-flesh and non blood-flesh individuals $(P$ values ranging from 0.452 to 0.745 ). These results, which were consistent during the 2 years of observation, are in agreement with a model based on a single dominant gene controlling the blood-flesh trait. We will refer hereafter to this trait as DBF (Dominant Blood-Flesh). Based on the results obtained in the first population (Table 2), we deduced that 'Wu Yue Xian' is homozygous for this trait.

SSR development, genetic linkage map construction and $D B F$ mapping

Among the 508 SSRs screened between the two parents, 473 SSRs generated amplification products. Among these SSRs, only 132 and 40 were useful for mapping in 'D6090' and 'Honey Blaze ${ }^{\circledR}$, , respectively. Different levels of heterozygosity were observed between the two parents and among LG (Table 3). The percentage of heterozygous loci varied from $33.9 \%$ (LG6) to $61.1 \%$ (LG4) in 'D6090', averaging 44.6\%. The percentage of heterozygous loci varied from $16.2 \%$ (LG2) to 39.4\% (LG5) in 'Honey Blaze ${ }^{\circledR}$, averaging only 23.3\%. The percentage of markers that was useful for mapping was approximately $27.9 \%$ for 'D6090' and varied from $11.3 \%$ (LG5) to $44.4 \%$ (LG4). The lowest percentages were observed in LG5 and LG6. The percentage was only $8.5 \%$ on average for 'Honey Blaze ${ }^{\circledR}$, and varied from as low as $2.8 \%$ (LG4) to $23.5 \%$ (LG3). Only one marker was useful for mapping in LG4 and LG7 of 'Honey Blaze ${ }^{\circledR}$, in which 36 and 35 SSRs were screened, respectively. In addition, only portions of the other groups could be constructed. Consequently, only the map of 'D6090' was developed to study the blood-flesh trait, which will hereafter be referred to as the 'D6090' map.

A total of 102 SSR loci and $D B F$ were mapped to the expected 8 linkage groups with an LOD score of 3.0 (Fig. 6). Two SSRs, CPDCT028 and MA013a, were discarded from the mapping set due to scoring difficulties. No segregation distortion was observed. The 'D6090' map covered a total distance of $562.3 \mathrm{cM}$, with an average distance of $5.46 \mathrm{cM}$ being observed between markers. Marker density differed between linkage groups. LG5 exhibited the highest marker density, with an average distance of $3.50 \mathrm{cM}$ between markers, and LG7 displayed the lowest marker density $(10.24 \mathrm{cM})$. Twelve gaps with a distance of more than $15.0 \mathrm{cM}$ remained in the 8 linkage groups due to the high similarities of the two parents in these regions.

We did not observe any translocation events or misordered markers compared to the $\mathrm{T} \times \mathrm{E}$ map, except for ВРРСТ030 and ВРPCT024, which were located on LG2 at inverted positions (Fig. 6), and no segregation distortion was detected. However, 7 SSRs (AMPPG027, AMPPG016, AMPA93 (LG1), pchgms1, MA007a (LG2), AMPA107 and pchgms27 (LG7) were found at inverted or misplaced positions compare to the Prunus persica v1.0 genome sequence, despite each of them mapped at a single locus. The linkage groups covered $50.2 \%$ to $96.9 \%$ of the corresponding scaffolds, with an average of $69.6 \%$ being observed. The highest coverage (96.9 \%) was found for LG1, followed by LG2 (78.8 \%), LG8 (74.6\%), LG7 (74.0\%), LG3 (64.7\%) and LG6 (61.0\%). In LG4 and LG5, only 56.7\% and 50.2\% coverages were obtained, respectively. All of the markers were ordered in accordance with the corrected peach genome sequence v1.0 alignment (Verde et al., 2013).

$D B F$ was mapped in LG5 with several markers being tightly linked on both sides (Fig. 6). Only one recombinant was observed between $D B F$ comprising the loci AMPPG144, AMPPG152 and AMPPG157 on the 
Version préliminaire du manuscrit publié dans / Preliminary version of the manuscript published in :

1 Tree Genetics and Genomes (2013), 19 p., DOI: no data

1 Journal homepage: http://link.springer.com/journal/11295

one hand, and on the other, the loci AMPPG178 and CPPCT040. According to the positions of the markers in the peach genome sequence v1.0, $D B F$ was localized to a $505 \mathrm{kbp}$ region of LG5 between 442,411 and 947,087 bp from the origin (Fig. 6).

In silico candidate gene analysis

We first examined whether homologs of genes known for their involvement in the control of red-flesh phenotype in other rosaceous species were located at the top of LG5 in the $505 \mathrm{kbp}$ region containing $D B F$. We have localized PprMYB10, peach homolog of MdMYB10, a MYB transcription factor gene responsible for both red foliage and red-fleshed fruit in apple, to LG3 (identified as ppm016711m, spanning from nucleotide position $12,840,372$ to $12,842,225$ ) clustered with two others MYB homologs (ppa026640m, ppa020385m). Therefore, PprMYB10 is not located in the $D B F$ region and cannot be considered as candidate for controlling $D B F$ phenotype.

The reference genome sequence of peach v1.0 corresponding to the $D B F$ region was then investigated to identify other CGs that might potentially be involved in the phenotypic expression of $D B F$. 64 predicted genes were found in the region. No functional annotation corresponding to transcription factors involved in regulation of anthocyanin pathway (MYB, $b H L H$ or $W D$ gene families) was detected among these genes. Interestingly, a cluster of three candidate transcripts (ppa008796m, ppa008758m and ppa008751m) displays similarity to dihydroflavonol-4-reductase gene family that encodes one of the key enzyme in anthocyanin biosynthetic pathway. Their genomic sequences are located in an interval between 594,087 and 610,895 bp from the top of LG5.

\section{Discussion}

'Wu Yue Xian' blood-flesh phenotype and inheritance

Our results clearly demonstrated that the blood-flesh phenotype observed in 'Wu Yue Xian' is different from that determined by the $b f$ locus. Both are characterized by high anthocyanin accumulation in the mesocarp of ripe fruit. However, the blood-flesh phenotype exhibited by 'Wu Yue Xian' was mainly characterized by intense anthocyanin accumulation only during the later stages of fruit development, green midrib and normal growth of the tree. This blood-flesh phenotype is identical to that described in 'Indian Cling' (Werner et al. 1998; Okie 1998). In contrast, this phenotype differs from other blood-flesh phenotypes expressed in old French blood-flesh cultivars and 'Harrow Blood', which show early expression of anthocyanin in fruit mesocarp, together with a red midrib leaf and reduction in tree vigor (Werner et al. 1998; Chapparo et al. 1995). The red pigmentation observed in the mesocarp of fruits produced by 'Wu Yue Xian' was also higher and more intense, associated with a brighter and less red-violet tone. These findings provide the basic phenotypic criteria for easily distinguishing between the two blood-flesh traits observed in peach.

Inheritance studies performed in the four successive generations derived from 'Wu Yue Xian' clearly showed that the blood-flesh trait exhibited by this Chinese accession was controlled by a single dominant locus. The dominant determinism of this blood-flesh trait is therefore different from that determined by the $b f$ locus in

\section{Comment citer ce document}

Shen , Z. ., Confolent, C., Lambert, P., Poëssel, J.-L., Quilot-Turion, B., Yu , M. . (Auteur 
Version préliminaire du manuscrit publié dans / Preliminary version of the manuscript published in :

\section{Tree Genetics and Genomes (2013), 19 p., DOI: no data \\ 1 Journal homepage: http://link.springer.com/journal/11295}

'Harrow Blood', which is under the control of a single recessive locus (Werner et al., 1998). We propose to designate this locus DBF (Dominant Blood-Flesh) in reference to the recessive bf locus. 'Wu Yue Xian' was found to be homozygous for this locus.

Regulatory genes controlling the expression of structural genes involved in the anthocyanin biosynthetic pathway have been identified in many plants. The expression of these structural genes, which are coordinately regulated and expressed in response to genetic, developmental and environmental cues, is controlled by a number of regulatory genes that condition anthocyanin production in particular tissues (Xie et al. 2011, Holton and Cornish 1995). The expression variability of the anthocyanic pigments within the two distinct blood-flesh phenotypes investigated in this work suggests that anthocyanin production is likely under different regulatory controls in the different observed organs. Opposite genetic determinism observed (dominant/recessive) in these genotypes strengthens this assumption. Peach cultivars exhibiting separately these two blood-flesh phenotypes, in addition to the one determined by the $C S$ locus, which controls the red pigmentation around the stone (Yamamoto et al. 2005; 2001), thus constitute good models for studying specific genes regulating anthocyanin biosynthesis in the mesocarp of fruit.

Genetic linkage map and $D B F$ mapping

Since the first map of Prunus persica was published by Chaparro et al. (1994), more than 30 maps have been developed in different Prunus populations using different types of markers (Arús et al. 2012; Pozzi and Vecchietti 2009), with the most recent ones being constructed based on SNPs (Martínez-García et al. 2013). Most of these maps contain a set of markers shared with the general Prunus map ( $\times$ E ) (Dirlewanger et al. 2004). Moreover, following the release of the peach genome sequence v1.0 (Verde et al. 2013), markers in T×E have been anchored to the peach sequence framework. This allows the identification of linkage groups, comparison of marker positions and the evaluation of coverage. These maps have been developed for the genetic analysis of simple Mendelian characters and QTLs involved in agronomic traits of breeding interest. All these analyses were well summarized in recent publications (Verde et al. 2013; Arús et al. 2012). It should be added, however, the blood-flesh trait ( $b f$ locus) that was first mapped to the top of the LG4 by Gillen and Bliss (2005), based on a genetic linkage map from an $F_{2}$ population derived from self-pollination of a single $F_{1}$ plant of the peach intra-specific population 'Harrow Blood' x 'Okinawa'.

In this study, we constructed a genetic map derived from a population segregating for the blood-flesh phenotype and identified a locus $(D B F)$ involved in determining this character. Among 102 SSRs mapped for 'D6090', 32 were shared with T×E. All eight linkage groups aligned with their respective groups in $T \times E$. In addition, the ordering and positions of markers were compared with the peach genome sequence v1.0. Genome positions were clearly identified for 84 SSRs mapped in the 'D6090' map, and positions were partially determined for 12 additional SSRs for which only one primer could be positioned. Among the SSRs included in this map, 89 were ordered in accordance with the original peach genome sequence, but seven were found at different locations than would be expected from the peach sequence. These SSRs mapped to inverted or misplaced positions in LG1, LG2, LG7 and LG3. However, these locations were in accordance with the corrected published version of the peach genome sequence (Verde et al. 2013), as several LG have been found to be misordered or misplaced in the original version (v1.0), notably LG1, 2, 3, 6 and 7. In addition, two SSRs 
Version préliminaire du manuscrit publié dans / Preliminary version of the manuscript published in :

\section{Tree Genetics and Genomes (2013), 19 p., DOI: no data \\ 1 Journal homepage: http://link.springer.com/journal/11295}

mapped to LG2 at inverted positions compared to $\mathrm{T} \times \mathrm{E}$ were found at similar positions in the peach genome sequence and with the same order as in 'D6090', showing that the whole-genome sequence is more reliable than the $\mathrm{T} \times \mathrm{E}$ genetic map. The peach genome sequence v1.0 was also successfully used to develop new SSRs in the $505 \mathrm{kbp}$ region surrounding the $D B F$ locus to LG5. This demonstrates that the peach sequence is an efficient tool for comparing mapping alignments and designing markers, as all of the developed SSR primer pairs generated PCR products and allowed the interval between the $D B F$ locus and the adjacent SSRs to be reduced. This could help to identify candidate genes more easily.

As regard to the localization on the peach genome of traits responsible for red flesh color, only two single loci were previously mapped in peach: the Cs locus mapped in the central part of LG3, responsible for red color of the mesocarp around the stone (Yamamoto et al. 2005; 2001); and the $b f$ locus mapped to the top of LG4 (Gillen and Bliss 2005), which controls an intense red pigmentation of the mesocarp in unripe and ripe fruit. One of the main findings of this study was to map a new single blood-flesh trait, designed $D B F$, to the top of the LG5, responsible for red fully mesocarp only in ripening fruit. That proves first that $D B F$ and $b f$ loci are not alleles. Identification of new genomic regions involved in the control of this trait, also strengthens the idea that different genes could be responsible for the level of flesh anthocyanic color in peach. It is an important step which should facilitate the research of genes underlying the control of red flesh color, due to anthocyanins, in peach.

Putative candidate genes for the $D B F$ trait

Red-fleshed fruit traits were previously mapped in other species belonging to the Rosaceae family. In apple, numerous studies focused on red flesh have been performed in recent years. The Rni locus, controlling both red foliage and red-fleshed fruit phenotypes, was mapped to LG9 in apple (Chagné et al. 2007). The transcription factor MdMYB10 has been shown to co-segregate with Rni and was proposed to be the gene controlling the red flesh trait (Chagné et al. 2007). Espley et al. (2009) found a minisatellite-like structure, $R_{6}$, composed of tandem repeats (23 bp) in the upstream promoter region of MdMYB10 that is only present in red foliage apple varieties and species. These authors demonstrated that $R_{6}$ is responsible for increasing MYB10 transcript levels and the subsequent ectopic accumulation of anthocyanins. However, a study by Sekido et al. (2010) showed that the redflesh trait of the apple cultivar 'Pink Pearl' might be controlled by a gene other than MdMYB10. The gene they identified that controls the red flesh trait is close to the S3-RNase allele in LG17. More recently, van Nocker et al. (2012) identified $R_{6}$ loci in Malus collections representing more than 3,000 accessions and found that, although $R_{6}$ was strongly associated with red-fleshed fruit, this allele was neither sufficient nor necessary to generate blood-flesh in all genotypes. These studies suggest that diverse genes could be responsible for the red flesh character in apple. In sweet cherry (Prunus avium L.), Sooriyapathirana et al. (2010) mapped a major QTL controlling red skin and red flesh color to LG3 and two minor QTLs to LG6 and LG8. The candidate gene PavMYB10, which is homologous to apple MdMYB10, was found to be located inside the interval of the major QTL. Therefore, PavMYB10 was proposed to be the major determinant gene controlling fruit skin and flesh coloration in sweet cherry. PprMYB10 was also identified in peach by Lin-Wang et al. (2010). By aligning the coding sequence of the gene with the peach genome, we localized PprMYB10 to LG3 in the peach genome. This location is in accordance with that of PavMYB10 in LG3 in the sweet cherry genome and is positioned in the 
Version préliminaire du manuscrit publié dans / Preliminary version of the manuscript published in :

Tree Genetics and Genomes (2013), 19 p., DOI: no data

1 Journal homepage: http://link.springer.com/journal/11295

2

region of the $\mathrm{Ag}$ locus in LG3 in almond and of the $\mathrm{Cs}$ locus in LG3 in peach, which determine the yellow/anthocyanic color of anthers (Joobeur 1998) and the red pigmentation of the flesh around the stone (Yamamoto et al. 2005), respectively. The location of PprMYB10 in LG3 clearly shows that this candidate gene is not directly involved in the control of the $D B F$ trait, as well as in that of the $b f$.

Using the gene prediction and annotation file generated from the peach genome sequence v1.0, we found 64 predicted genes in the $505 \mathrm{~kb} D B F$ region located in LG5. None of these annotated genes showed homology to PprMYB10, MYB, $b H L H$ or $W D$, which encode transcription factors that are usually involved in the regulation of the anthocyanin biosynthetic pathway and the control of fruit pigmentation (Petroni and Tonelli, 2011). This suggests that these gene families are not candidates for the control of the $D B F$ character and that the gene underlying $D B F$ could be different from that found in most red flesh apple cultivars and in sweet cherry. Interestingly, we found a cluster of three members of the dihydroflavonol-4-reductase $(D F R)$ gene family in this region. $D F R$ genes control a key step in the biosynthesis of anthocyanins and can act as a switch for the control of red coloration in organs of other plants (Martins et al. 2013). Therefore, these three DFR genes appear to be good candidates for the control of the $D B F$ trait. Further work will be necessary to confirm whether one of these three $D F R$ genes is involved in the control of this new dominant blood-flesh trait discovered in peach collections from China.

Consequences for breeding

The transmission of the blood-flesh trait determined by the $D B F$ locus would be more efficient than that controlled by the $b f$ locus because of its dominant mode of inheritance, which should allow peach breeders to obtain this trait in each generation. Moreover, the fully red mesocarp of the fruits associated with the $D B F$ trait might be more attractive to the consumer than those associated with the $b f$ trait, which often displays a red pigmentation gradient extended more or less from the epidermis to stone. Therefore, individual fruits exhibiting both the $D B F$ phenotype and good agronomic features, such as some of the fruits from the HD population (Fig. 4), constitute good candidates for use as elite genitors for developing a full range of blood-flesh peaches and nectarines. Furthermore, SSR markers flanking the DBF locus, such as AMPP157 and AMPPG178, provide a good basis for the MAS of favorable individuals at the plantlet stage and, thus, for increasing the efficiency of the peach breeding programs that have already been initiated at INRA-Avignon (France) for this blood-flesh trait.

Acknowledgements This work is currently funded by the European Union through the FP7 Marie Curie International Research Staff Exchange Scheme (IRSES) KBBE-246795 (STONE acronym). We are grateful to Veronique Decroocq (INRA IBVM, UMR GDPP, Villenave d'Ornon, France) who initiated the collaboration between INRA (France) and JAAS (Chine). This work also was funded by grants from the INRA through the IVD4 project established under the Convention INRA/Agri-Obtentions (InnovaFruit acronym). The authors thank the technical staff of the INRA Experimental Farm "Domaine des Pins de L'Amarine" for growing the plant material in orchard, and V. Signoret for technical assistance.

\section{References}


Version préliminaire du manuscrit publié dans / Preliminary version of the manuscript published in :

1 Tree Genetics and Genomes (2013), 19 p., DOI: no data

1 Journal homepage: http://link.springer.com/journal/11295

3

4

Abajian C (1994) Sputnik program+, http://www.abajian.com/sputnik

Arús P, Verde I, Sosinski B, Zhebentyayeva T, Abbott AG (2012) The peach genome. Tree Genet Genomes, 8:531-547

Bernatzky R, Tanksley SD (1986) Genetics of actin-related sequences in tomato. Theor Appl Genet 72:314-321

Butelli E, Titta L, Giorgio M, Mock HP, Matros A, Peterek S, Schijlen EG, Hall RD, Bovy AG, Luo J, Martin C (2008) Enrichment of tomato fruit with health-promoting anthocyanins by expression of select transcription factors. Nature Biotechnology 26:1301-1308

Cevallos-Casals BA, Byrne D, Okie WR, Cisneros-Zevallos L (2006) Selecting new peach and plum genotypes rich in phenolic compounds and enhanced functional properties. Food Chem 96:273-280

Chagné D, Carlisle CM, Blond C, Volz RK, Whitworth CJ, Oraguzie NC, Crowhurst RN, Allan AC, Espley RV, Hellens RP, Gardiner SE (2007) Mapping a candidate gene (MdMYB10) for red flesh and foliage colour in apple. BMC Genomics 8:212

Chaparro JX, Werner DJ, O'Malley D, Sederoff RR (1994) Targeted mapping and linkage analysis of morphological isozyme, and RAPD markers in peach. Theor Appl Genet, 87:805-815

Chaparro JX, Werner DJ, Whetten RW, O'Malley DM (1995) Inheritance, genetic interaction and biochemical characterization of anthocyanin phenotypes in peach. J Hered 86:32-38

Dirlewanger E, Graziano E, Joobeur T, Garriga-Calderé F, Cosson P, Howad W, Arús P (2004) Comparative mapping and marker assisted selection in Rosaceae fruit crops. Proc Nat Acad Sci USA 101:9891-9896

Dragsted LO, Krath BN, Ravn-Haren LG, Vogel UB, Vinggaard AM, Jensen PB, Loft S, Rasmussen SE, Sandström B, Pedersen A (2006) Biological effects of fruit and vegetables. Proc Nutr Soc 65:61-67

Espley RV, Brendolise C, Chagné D, Kutty-Amma S, Green S, Volz R, Putterill J, Schouten HJ, Gardiner SE, Hellens RP, Allan AC (2009) Multiple repeats of a promoter segment causes transcription factor auto regulation in red apples. The Plant Cell 21:168-183

Feild TS, Lee DW, Holbrook NM (2001) Why leaves turn red in autumn. The role of anthocyanins in senescing leaves of red-osier dogwood. Plant Physiol 127(2):566-574

Gillen AM and Bliss FA (2005) Identification and mapping of markers linked to the Mi gene for root-not nematode resistance in peach. J Amer Soc Hort Sci 130(1): 24-33

Holton TA, Cornish EC (1995) Genetics and biochemistry of anthocyanin biosynthesis. The Plant Cell 7:10711083

Hsia CL, Luh BS and CO Chichester (1965) Anthocyanin in freestone peaches. J Food Sci 30:5-12

Jaeger SR and Harker FR (2005) Consumer evaluation of novel kiwifruit: willingness-to-pay. J. Sci Food Agr $85: 2519-2526$

Joobeur T (1998) Construction of a molecular marker map and genetic analysis of agronomic characters in Prunus. Ph.D. thesis dissertation, University of Lleida, Spain

Kosambi DD (1944) The estimation of map distance from recombination values. Ann Eugen Report, Cambridge 12:172-175

Lambert P, Pascal T (2011) Mapping $R m^{2}$ gene conferring resistance to the green peach aphid (Myzus persicae Sulzer) in the peach cultivar "Rubira ${ }^{\circledR}$ ". Tree Genet Genomes 7: 057-1068

Lincoln SE, Daly MJ, Lander ES (1992) Constructing genetic maps with Mapmaker/exp 3.0, 3rd edn. Whitehead Institute Technical

Lin-Wang K, Bolitho K, Grafton K, Kortstee A, Karunairetnam S, McGhie TK, Espley RV, Hellens RP, Allan AC (2010) An R2R3 MYB transcription factor associated with regulation of the anthocyanin biosynthetic pathway in Rosaceae. BMC Plant Biol 10:50

Lu SY, Yu ML, Ma RJ, Shen ZJ (2010) Analysis of genetic diversity and relationship of crisp peach by SSR. J Plant Genet Resources 11(3):374-379

Martínez-García PJ, Parfitt DE, Ogundiwin EA, Fass J, Chan HM, Ahmad R, Lurie S, Dandekar A, Gradziel TM, Crisosto CH (2013) High density SNP mapping and QTL analysis for fruit quality characteristics in peach (Prunus persica L.). Tree Genet Genomes 9:19-36

Martins TR, Berg JJ, Blinka S, Rausher MD, Baum DA (2013) Precise spatio-temporal regulation of the anthocyanin biosynthetic pathway leads to petal spot formation in Clarkia gracilis (Onagraceae). New Phytol 197:958-969

Okie WR (1998) Handbook of peach and nectarine varieties: performance in the southeastern United States and index of names. US Dept Agr Hdbk No. 714

Pascal T, Monteux-Caillet R (1998) Peach breeding in France. Acta Hort 465:117-123

Petroni K, Tonelli C (2011) Recent advances on the regulation of anthocyanin synthesis in reproductive organs. Plant Science 181:219-229

Pozzi C, Vecchietti A (2009) Peach structural genomics. In: Folta KM, Gardiner SE (eds) Genetics and genomics of Rosaceae. Springer, New York, pp 235-257 
Version préliminaire du manuscrit publié dans / Preliminary version of the manuscript published in :

Tree Genetics and Genomes (2013), 19 p., DOI: no data

1 Journal homepage: http://link.springer.com/journal/11295

2

Regan BC, Julliot C, Simmen B, Vienot F, Charles-Dominique P, Mollon JD (2001) Fruits, foliage and the evolution of primate colour vision. Philos Trans R Soc Lond B Biol Sci 356(1407):229-283

Ross JA, Kasum CM (2002) Dietary flavonoids: Bioavailability metabolic effects, and safety. Annu Rev Nutr 22:19-34

Scorza R, Sherman WB, 1996. Peaches, p. 325-340. In: J Janick and JN Moore (eds). Fruit breeding. vol. 1. Tree and tropical fruits. Wiley. New York

Sekido K, Hayashi Y, Yamada K, Shiratake K, Matsumoto S, Maejima T, Komatsu H (2010) Efficient breeding system for red-fleshed apple based on linkage with S3- RNase allele in 'Pink Pearl'. HortSci 45:534-537

Shin WH, Park SJ, Kim EJ (2006) Protective effect of anthocyanins in middle cerebral artery occlusion and reperfusion model of cerebral ischemia in rats. Life Sciences 79:130-137

Sooriyapathirana SS, Khan A, Sebolt AM, Wang D, Bushakra JM \& Wang KL, Allan CA, Gardiner SE, Chagné D, Iezzoni AF (2010) QTL analysis and candidate gene mapping for skin and flesh color in sweet cherry fruit (Prunus avium L.). Tree Genet Genomes 6:821-832

Tanaka Y, Sasaki N, Ohmiya A (2008) Biosynthesis of plant pigments: anthocyanins, betalains and carotenoids. Plant J 54(4):733-749

van Blaricom LO, Senn TL (1967) Anthocyanin pigments in freestone peaches grown in the Southeast. Proc Am Soc Hort Sci 90:541-545

van Nocker S, Berry G, Najdowski J, Michelutti R, Luffman M, Forsline P, Alsmairat N, Beaudry R, Nair MG, Ordidge M (2012) Genetic diversity of red-fleshed apples (Malus). Euphytica 185:281-293

Verde I, Abbott AG, Scalabrin S, Jung S, Shu S, Marroni F, Zhebentyayeva T, Dettori MT, Grimwood J, Cattonaro F, Zuccolo A, Rossini L, Jenkins J, Vendramin E, Meisel LA, Decroocq V, Sosinski V, Prochnik S, Mitros T, Policriti A, Cipriani G, Dondini L, Ficklin S, Mgoodstein D, Xuan P, Del Fabbro C, Aramini V, Copetti D, Gonzalez S, Shorner D, Falchi R, Lucas S, Mica E, Maldonado J, Lazzari B, Bielenberg D, Pirona R, Miculan M, Barakat A, Testolin R, Stella1 A, Tartarini S, Tonutti P, Arús P, Orellana A, Wells C, Main D, Vizzotto G, Silva H, Salamini F, Schmutz J, Morgante M \& DS Rokhsar (2013) The high-quality draft genome of peach (Prunus persica) identifies unique patterns of genetic diversity, domestication and genome evolution. Nat Gen doi:10.1038/ng.2586

Vinson J, Zubik L, Bose P, Samman N, Proch J (2005) Dried fruits: excellent in vitro and in vivo antioxidants. J Am Coll Nutr 24: 44-50

Volz R, Oraguzie N, Whitworth C, How N Chagné D, Carlisle C, Gardiner S, Rikkerink E, and Lawerence T (2009) Breeding for red flesh colour in apple: progress and challenges. Acta Hort 841:337-342

Voorrips RE (2002) MapChart: software for the graphical presentation of linkage maps and QTLs. J Hered 93(1):77-78

Wang ZH, Zhuang EJ (2002) Monograph for Chinese Fruits. Peach. Chinese Forest Press, Beijing

Werner DJ, Creller MA, Chaparro JX (1998) Inheritance of the blood-flesh trait in peach. Hortscience 33(7):1243-1246

Williams CM, Mohsen M, Vauzour D, Rendeiro C, Butler LT, Ellis JA, Whiteman M, Spencer JPE (2008) Blueberry-induced changes in spatial working memory correlate with changes in hippocampal CREB phosphorylation and brain-derived neurotrophic factor (BDNF) levels. Free Radic Biol Med 45:295-305

Winkel-Shirley B (2001) Flavonoid biosynthesis. A colorful model for genetics, biochemistry, cell biology, and biotechnology. Plant Physiol 126(2):485-493

Xie R, Zheng L, He S, Zheng Y, Yi S, Deng L (2011) Anthocyanin biosynthesis in fruit tree crops: Genes and their regulation. African J Biotech Vol. 10(86):19890-19897

Xu Q, Yu K, Zhu A, Ye J, Liu Q, Zhang J, Deng X. (2009) Comparative transcripts profiling reveals new insight into molecular processes regulating lycopene accumulation in a sweet orange (Citrus sinensis) red-flesh mutant. BMC Genomics 10:540

Yamamoto T, Yamaguchi M, Hayashi T (2005) An integrated genetic linkage map of peach by SSR, STS, AFLP and RADP. J Japan Soc Hort Sci 74(3):204-213

Yamamoto T, Shimada T, Imai T, Yaegaki H, Haji T, Matsuta N,Yamaguchi M, Hayashi T (2001) Characterization of morphological traits based on a genetic linkage map in peach. Breed Sci 51:271-278 


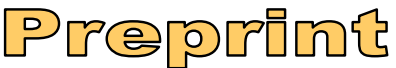

Version préliminaire du manuscrit publié dans / Preliminary version of the manuscript published in :

\section{Tree Genetics and Genomes (2013), 19 p., DOI: no data \\ 1 Journal homepage: http://link.springer.com/journal/11295}

Table 1 Comparison of anthocyanin pigmentation in organs of the two groups of peach to blood-flesh

\begin{tabular}{|c|c|c|c|c|c|c|c|c|}
\hline Group & Peach cultivar & $\begin{array}{l}\mathrm{n}^{\circ} \text { of } \\
\text { clone }\end{array}$ & Origin & $\underset{a, b}{\text { Stem }}$ & $\underset{\mathrm{a}}{\text { Petiole }}$ & $\begin{array}{c}\text { Red } \\
\text { midrib } \\
\text { leaf } \\
\text { a }\end{array}$ & $\begin{array}{c}\text { Mesocarp } \\
\text { of unripe } \\
\text { fruit (pit } \\
\text { hardening) } \\
\text { a }\end{array}$ & $\begin{array}{c}\text { Mesocarp } \\
\text { of } \\
\text { ripe } \\
\text { fruit } \\
\text { a }\end{array}$ \\
\hline $1^{\text {st }}$ & Wu Yue Xian ${ }^{c}$ & S 4566 & China & NA & NA & 0 & 0 & +++ \\
\hline $1^{\text {st }}$ & I138 & S 9337 & INRA (Fr) & + & + & 0 & 0 & +++ \\
\hline $1^{\mathrm{st}}$ & II016 & S 9755 & INRA (Fr) & + & + & 0 & 0 & +++ \\
\hline $1^{\mathrm{st}}$ & D6090 & S 9306 & INRA (Fr) & + & + & 0 & 0 & +++ \\
\hline $2^{\text {nd }}$ & Harrow Blood ${ }^{c}$ & $795-1$ & USA & ++ & ++ & +++ & +++ & +++ \\
\hline $2^{\text {nd }}$ & Sanguine Super Tardive* & S 7916 & Guillot Nurseries (Fr) & ++ & ++ & +++ & +++ & +++ \\
\hline $2^{\text {nd }}$ & Sanguine Pilat* & S 7913 & Magnard-peach grower $(\mathrm{Fr})$ & ++ & ++ & +++ & +++ & +++ \\
\hline $2^{\text {nd }}$ & Sanguine Vineuse* & S 4577 & Moreau-peach grower $(\mathrm{Fr})$ & ++ & ++ & +++ & +++ & +++ \\
\hline $2^{\text {nd }}$ & R6041 & S 9341 & INRA (Fr) & ++ & ++ & +++ & +++ & +++ \\
\hline $2^{\text {nd }}$ & R6044 & S 9756 & INRA (Fr) & ++ & ++ & +++ & +++ & +++ \\
\hline $2^{\text {nd }}$ & $\mathrm{R} 6057$ & S 9757 & INRA (Fr) & ++ & ++ & +++ & +++ & +++ \\
\hline
\end{tabular}

Table 2 Blood/nonblood segregations observed in 4 populations derived from 'Wu Yue Xian'

\begin{tabular}{|c|c|c|c|c|c|}
\hline \multirow{2}{*}{ Family } & \multicolumn{2}{|c|}{ Number of hybrids observed } & \multirow{2}{*}{ Test ratio } & \multirow{2}{*}{$x^{2}(1 \mathrm{df})$} & \multirow{2}{*}{$P$ value } \\
\hline & Blood-flesh & Non blood-flesh & & & \\
\hline 'Wu Yue Xian' x ‘Redtop' & 159 & 0 & - & - & - \\
\hline 'I138’ x ‘O’Henry' & 41 & 44 & $1: 1$ & 0.11 & 0.745 \\
\hline ‘II016’ x ‘Bigtop ${ }^{\mathbb{E}}$ & 67 & 76 & $1: 1$ & 0.13 & 0.452 \\
\hline 'D6090' x 'Honey Blaze ${ }^{\mathbb{B}}$ & 42 & 38 & $1: 1$ & 0.20 & 0.655 \\
\hline
\end{tabular}

Table 3 Comparison of the number of heterozygous markers and useful markers for mapping between 'D6090' and 'Honey Blaze ${ }^{\circledR}$,

\begin{tabular}{lccccc}
\hline \multirow{2}{*}{$\begin{array}{l}\text { Linkage } \\
\text { group }\end{array}$} & Number of & \multicolumn{3}{c}{ 'D6090 } & \multicolumn{2}{c}{ Honey Blaze $^{(R)}$} \\
\cline { 3 - 6 } LG1 & SSRs screened & Heterozygote & Useful for mapping & Heterozygote & Useful for mapping $^{(23}$ \\
LG2 & 123 & $56(45.5 \%)$ & $44(35.8 \%)$ & $20(16.3 \%)$ & $9(7.3 \%)$ \\
LG3 & 68 & $35(51.5 \%)$ & $27(39.7 \%)$ & $11(16.2 \%)$ & $3(4.4 \%)$ \\
LG4 & 34 & $12(35.3 \%)$ & $9(26.5 \%)$ & $10(29.4 \%)$ & $8(23.5 \%)$ \\
LG5 & 36 & $22(61.1 \%)$ & $16(44.4 \%)$ & $7(19.4 \%)$ & $1(2.8 \%)$ \\
LG6 & 71 & $29(40.8 \%)$ & $8(11.3 \%)$ & $28(39.4 \%)$ & $6(8.5 \%)$ \\
LG7 & 39 & $20(33.9 \%)$ & $7(11.9 \%)$ & $8(13.6 \%)$ & $3(5.1 \%)$ \\
LG8 & 35 & $16(45.7 \%)$ & $9(25.7 \%)$ & $8(22.9 \%)$ & $1(2.9 \%)$ \\
uncertain LG & 16 & $13(41.9 \%)$ & $8(25.8 \%)$ & $12(38.7 \%)$ & $6(19.4 \%)$ \\
Total & 473 & $8(50.0 \%)$ & $4(25.0 \%)$ & $6(37.5 \%)$ & $3(18.8 \%)$ \\
\hline \multicolumn{2}{l}{ Note: Values outside and inside of the round brackets are the number and percentage of SSRs respectively }
\end{tabular}


Version préliminaire du manuscrit publié dans / Preliminary version of the manuscript published in :

1 Tree Genetics and Genomes (2013), 19 p., DOI: no data

2 Journal homepage: http://link.springer.com/journal/11295

Table 4 Positions and sequences of the simple sequence repeats (SSR) primer pairs newly designed and mapped in the 'Honey Blaze ${ }^{\circledR}$ ' $\mathrm{x}$ 'D6090' map

\begin{tabular}{|c|c|c|c|}
\hline SSR name & Position in the "peach v1.0" scaffolds & Forward primer 5'-3' & Reverse primer 5'-3' \\
\hline AMPPG008 & Scaffold_1 (8339638-8339861) & CTA GCA CTC CGC AAA TGA CA & CAT CAC GCG CAT ACC AAT AG \\
\hline AMPPG016 & Scaffold_1 (9161952-9162152) & TGG TGA TGC TAA TGG CAA GA & CAT GGT CTC TTC CCG TGA CT \\
\hline AMPPG027 & Scaffold_1 (10187690-10187799) & GAT CGA AGC CTC GAA ACA AC & TCT GTC CGA GTC CAA TTT CC \\
\hline AMPPG031 & Scaffold_1 (10404764-10404999) & GAG GCT TGG ATC CAG TTT CA & TTA GGG CAC AAA CCT TCC TG \\
\hline AMPPG032 & Scaffold_1 (10504031-10504223) & TGG GGG CTT GCT ATA GAG TG & CAT AAA GCG AGC AAG GTT CC \\
\hline AMPPG037 & Scaffold_1 (40715232-40715402) & AAT AGG CCC CAC AGG AAT CT & TAA TAG CTC CTG CCC AAT GC \\
\hline AMPPG054 & Scaffold_1 (45917673-45917841) & TCC GTC CTA AGG GAA CAA CA & GAT CCG TCA AAA CTC GGA GA \\
\hline AMPPG085 & Scaffold_2 (4732070-4732113) & GCT AAG GGA GAC TTG GCA GAG TCC G & CTC GAG TCC ATG TGT TAT TTT GGG C \\
\hline AMPPG104 & Scaffold_6 (15875081-15875104) & TCA GCT CTA TAA CGA AAG ATG AAG G & GGC ATT ACA ATT TTT GGG TCA T \\
\hline AMPPG110 & Scaffold_6 (16004533-16004566) & CTT CAA TGT GTG AAT GGC ACT T & GTG GAT GGT TGG TGA AGA ATT T \\
\hline AMPPG113 & Scaffold_6 (16054743-16054790) & TGC GTA TTG TAG TTG GAG GAC T & TGG GAG AGG AGG TAG TGA GTG T \\
\hline AMPPG115 & Scaffold_2 (4435049-4435384) & CTG ACC АTC TCT СТT ССТ AAG TGG & AAG ACA AAA GGT CGT CCT CTC C \\
\hline AMPPG120 & Scaffold_2 (4755706-4755795) & СТC CAT CAC AAA CCT GTG AAA A & TTC ACC ATT CTC TGT CTT TTG C \\
\hline AMPPG125 & Scaffold_4 (2089898-2089567) & AAG CCA TTC TTC GAT GTG TTT C & TTT GAA GTG GTT GCC CAA TAT C \\
\hline AMPPG126 & Scaffold_4 (2139623-2139949) & CTT TGT CTG GGG AGT TCT TTT G & AAA CAC CAG GGT AAT TCA GAG C \\
\hline AMPPG127 & Scaffold_4 (2580289-2580538) & AAC CTC CCA ACA GTG TGT ATC AA & TGT TAG AAT CTT TTA TGT ACC CTT CC \\
\hline AMPPG131 & Scaffold_4 (3047961-3048171) & CTG TCG TTT ATT TAG TGT CGT GGT & AAG GTA GGT GGA TTG GTT TGT C \\
\hline AMPPG143 & Scaffold_2 (5575538-5575970) & GCC CAG TAT CCT GGA TTG AA & GCT TCC CCA ACC TGA CAC TA \\
\hline AMPPG144* & Scaffold_5 (199428-199619) & TTG ATG CTG ACT CCA TCC AC & GCT CGA CAA TAA TGG CTG GT \\
\hline AMPPG152* & Scaffold_5 (282589-282782) & GAA GAC GAA TTG GAG GGA AA & TTT GCT CTC ATC TGC CAT TG \\
\hline AMPPG157* & Scaffold_5 (442159-442411) & GTT GCA ATG TGG TTC TAC CG & TCA CCA TTA TCC GCC TTT AG \\
\hline AMPPG178* & Scaffold_5 (947087-947234) & GGG CTC ACC TTG GTG TTA AA & GAA GCA GAC GCA GAA ACA CA \\
\hline
\end{tabular}

Those mapped in the $D B F$ region have an asterisk on the left

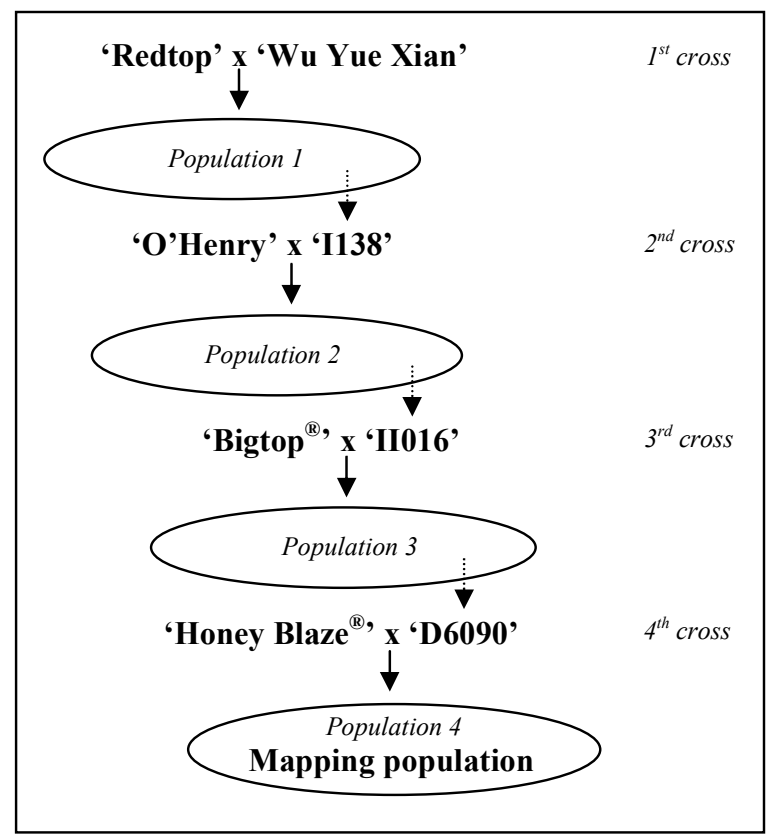

Fig. 1 Pedigree of the blood-flesh parents and the four successive generations produced for inheritance analysis 


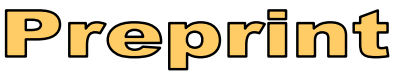

Version préliminaire du manuscrit publié dans / Preliminary version of the manuscript published in :

Tree Genetics and Genomes (2013), 19 p., DOI: no data

1 Journal homepage: http://link.springer.com/journal/11295

3

4

5

6

7

8
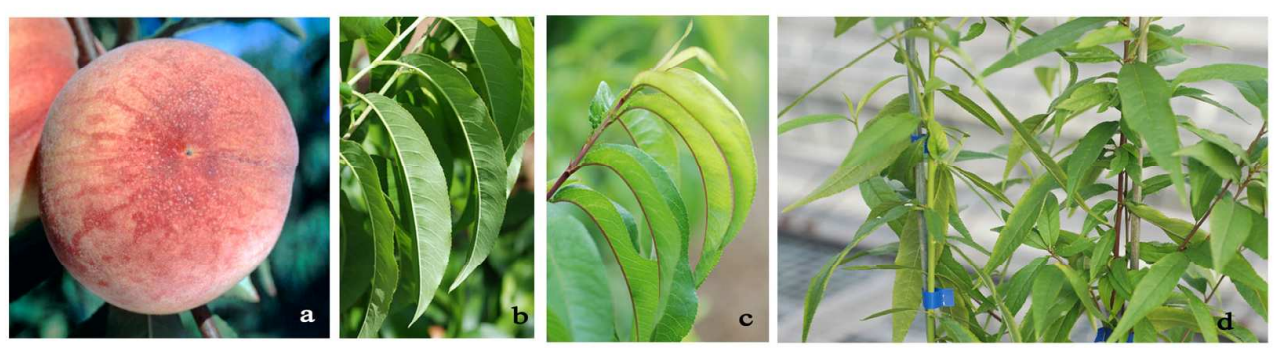

Fig. 2 (a) 'Wu Yue Xian' fruit; (b) 'Wu Yue Xian' leaves with green midrib; (c) 'Sanguine Super Tardive' leaves with red midrib; (d) stems with low levels of anthocyanin pigmentation (left) as in 'Wu Yue Xian' and with intermediate levels of anthocyanin pigmentation (right) as in 'Sanguine Super Tardive'

(a)
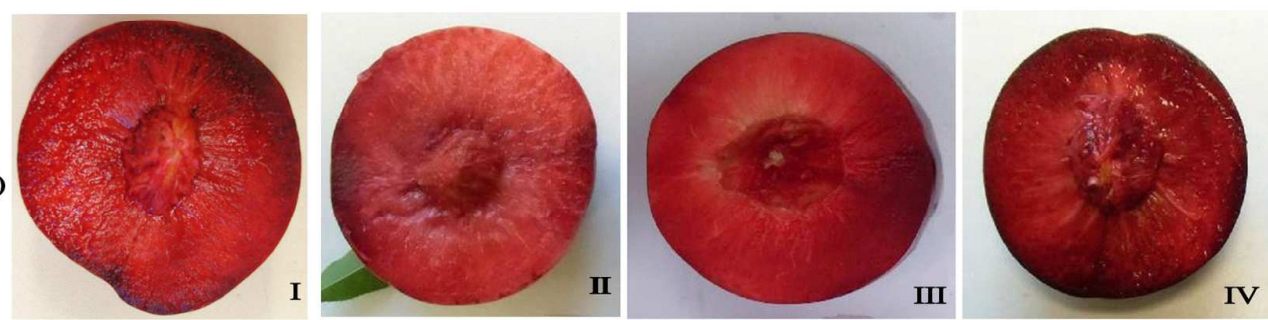

(b)
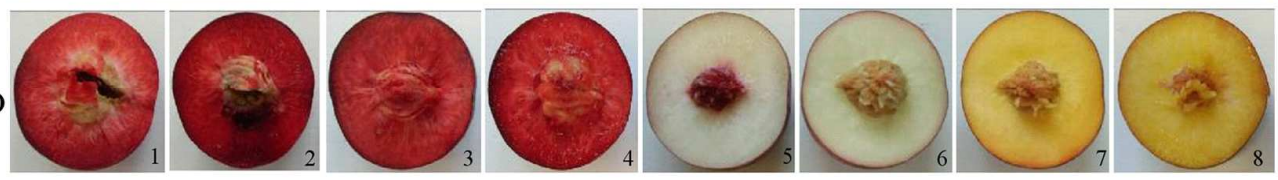

Fig. 3 (a) Fruit of blood-flesh parents. Parents numbers are as follows: 1, 'Wu Yue Xian'; II, 'I138'; III, 'II016', IV, 'D6090'; (b) Fruit representative of eight individuals from 'Honey Blaze' x 'D6090' population, illustrating segregation between blood (1-4) and nonblood (5-8) individuals
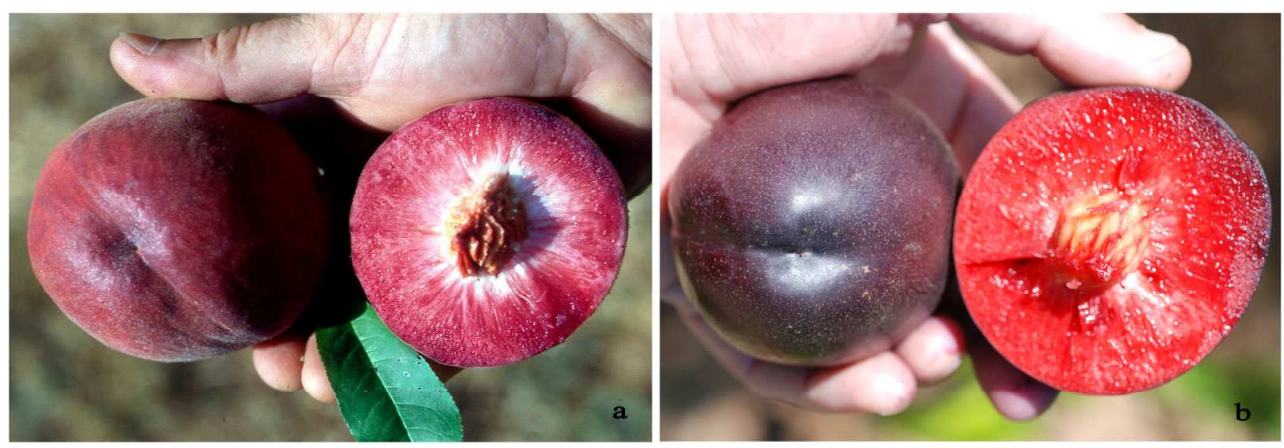

Fig. 4 (a) Fruit of an advanced selection derived from 'Sanguine Super Tardive', with the blood-flesh phenotype determined by the $b f$ locus; (b) Fruit of an advanced selection derived from 'Wu Yue Xian' ('Honey Blaze' $\mathrm{x}$ 'D6090'), with the blood-flesh phenotype determined by the DBF locus 
Version préliminaire du manuscrit publié dans / Preliminary version of the manuscript published in :

Tree Genetics and Genomes (2013), 19 p., DOI: no data

1 Journal homepage: http://link.springer.com/journal/11295

2

3

4

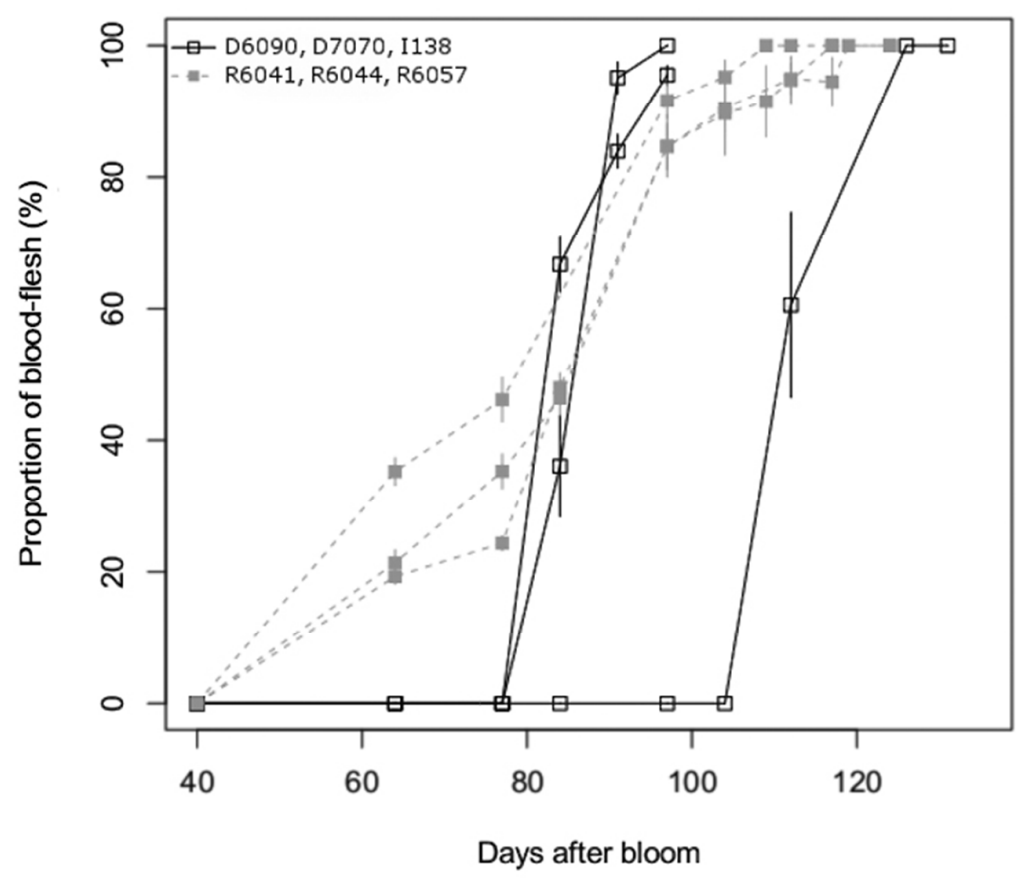

Fig. 5 Progression of the red pigmentation in the mesocarp during fruit development from blood-flesh peach selections derived from Chinese genitor 'Wu Yue Xian' (D6090, D7070, I138) and French genitors (R6041, R6044, R6057). Bars represent standard errors. 
Version préliminaire du manuscrit publié dans / Preliminary version of the manuscript published in :

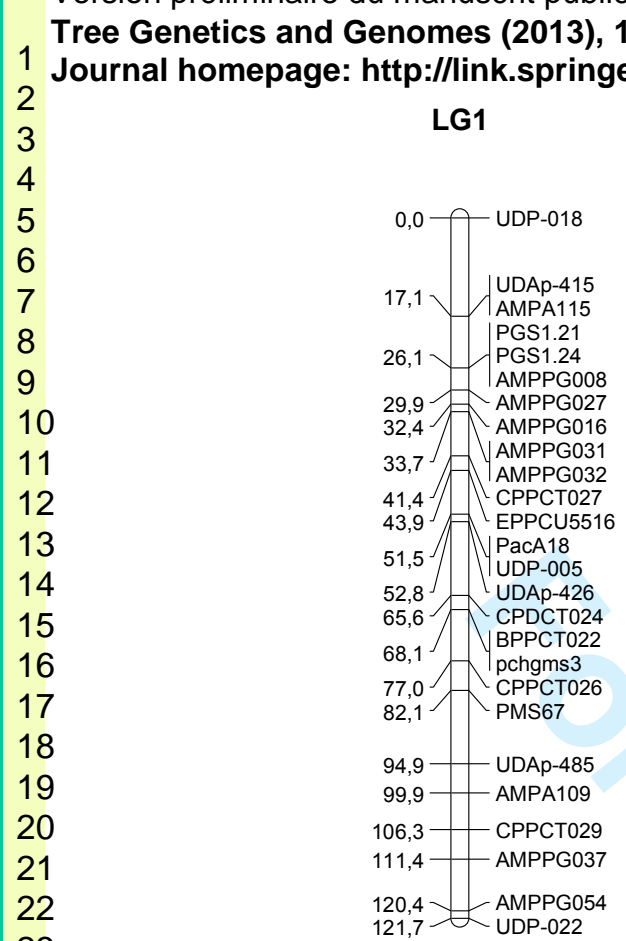

23

24

25

26

27

28

29

30

31

32

33

34

35

36

37

38

39

40

41

42

43

44

45

46

47

48

49

50

51

52

53

54

55

56

57

58

59

60
LG3

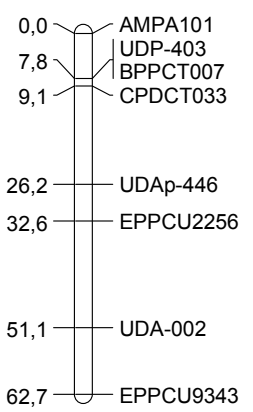

0,0 AMPA93

10,3
12,8

16,6 $\begin{aligned} & \text { MA024a } \\ & \text { UDP-025 }\end{aligned}$

38,1 لـ

40,6 - ВРPCT034

50,9- UDP-013

68,0 $]$ [ pchgms1

69,3

71,8 $=$ ВPРCT030

$73,1=$ BPPCT024

78,2 $\$ EPPCU1098

79,5 A CPSCT021

80,8 UDP-410

83,3 $\begin{aligned} & \text { UDP-406 } \\ & \text { PceGA34 }\end{aligned}$

LG7
LG4
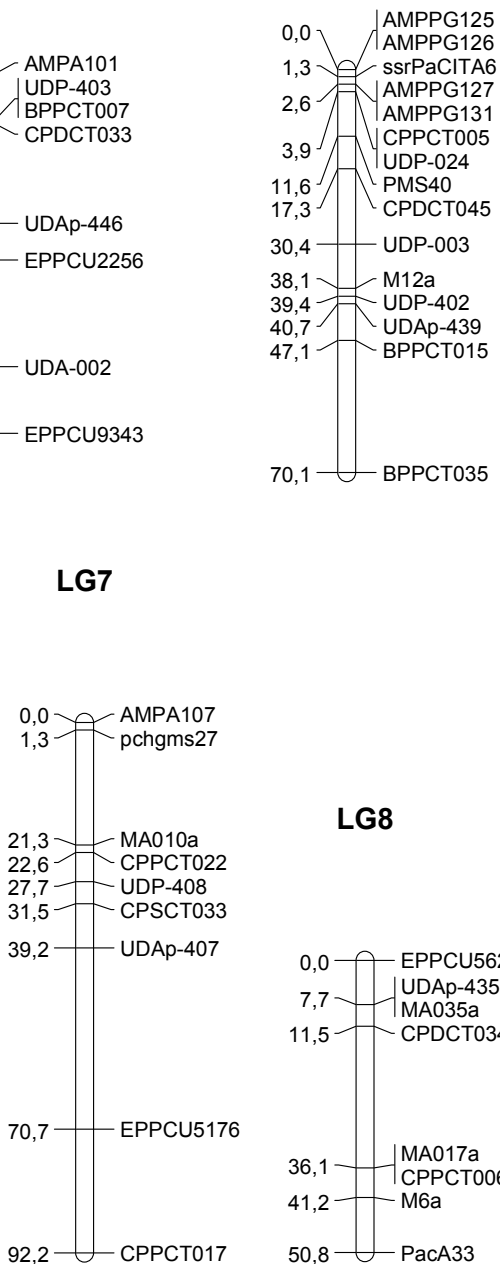

LG8

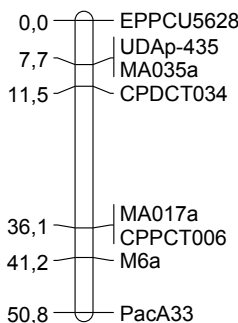

Fig. 6 Linkage map of 'D6090' derived from the 'Honey Blaze ${ }^{\circledR}$, $x$ 'D6090' population. Markers at inverted positions compared to $\mathrm{T} \times \mathrm{E}$ map are underlined. $D B F$ on LG5 is the blood-flesh phenotype. Positions on the peach genome scaffold_5 of SSRs closed to DBF are noted at the right of LG5. 